\title{
Pharmacy Services Reboot Roadmap: Resiliency During the COVID-19 Pandemic
}

L. Hayley Burgess PharmD, MBA, BCPP, CPPS, Joan S. Kramer PharmD, BCPS, CPPS, DPLA,' Brian Moran PharmD, MBA, 1,2 Mandelin Cooper PharmD, BCPS, Christine Dunn PharmD, ${ }^{1,2}$ Edward Murray PharmD, MBA, BCPS, Karla M. Miller PharmD, BCPP ${ }^{1}$

\section{Abstract}

\section{Description}

Planning for resumption of patient care services during and following the impact of novel coronavirus disease-2019 (COVID-19) while controlling costs are essential for pharmacy services resiliency. Implementation of a pharmacy services reboot roadmap across a 179 hospital health-system is described. The roadmap encompassed eight key areas: pharmacy leadership, staffing and scheduling, clinical pharmacy services, medication safety, medication supply, regulatory and compliance, team support opportunities, and financial stewardship. A supporting checklist and volume-based staffing plan are included as examples to assist pharmacy leaders in planning optimal pharmacy services support as patient volumes increase, particularly in the emergency department, surgical services and critical care areas. Resiliency strategies are provided as tangible planning considerations to assess the current status of, and prepare for, future operational and clinical pharmacy practice needs to support optimal patient care.

\section{Keywords}

COVID-19; SARS-CoV-2; coronavirus infections; pharmacy; pharmacist; hospital pharmacy service; roadmap; checklist; patient safety; health care sector; financial stewardship

\section{Introduction}

The first case of novel coronavirus disease 2019 (COVID-19) caused by severe acute respiratory coronavirus 2 (SARS-CoV-2) in the United States (U.S.) was reported on January 22, 2020, with numerous patients requiring hospitalization in subsequent months. ${ }^{1}$ Nearly $94.5 \%$ of the U.S. population was ordered to remain at home as COVID-19 quickly spread. ${ }^{2}$ Hospitals reported a significant decrease in the number of patients admitted for treatment of nonCOVID-19 associated conditions such as heart attacks, strokes, appendicitis and gallbladder infections. ${ }^{3}$ Such a change in behavior suggests people believe visiting a hospital may expose them to COVID-19. ${ }^{3}$

The American College of Surgeons, the Centers for Medicare and Medicaid Services and the Centers for Disease Control and Prevention were among the organizations that recommended hospitals to postpone or cancel elective surgeries for the purpose of conserving or shifting health care resources to manage the COVID-19 pandemic. ${ }^{4-6}$ The loss of revenue generated by elective surgeries, in addition the decrease in patients seeking treatment for non-COVID-19 associated conditions, has had a negative financial impact on many hospitals.,7 When stay at home orders were lifted, health systems and hospitals had to prepare to resume elective surgeries and other services that were postponed during the pandemic. ${ }^{4,6,8}$

As providers and nurses prepare to resume elective surgeries, procedures and routine health care visits, clinical pharmacists continue to optimize patient medication therapy, promote general health and perform vaccinations to prevent disease. To best prepare pharmacy services during and after the COVID-19 pan-

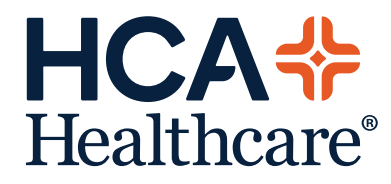

\section{www.hcahealthcarejournal.com}

(c) 2020 HCA Physician Services, Inc. d/b/a Emerald Medical Education
HCA Healthcare Journal of Medicine 
demic, pharmacist leaders in our health system created a reboot roadmap across 179 hospitals encompassing 8 key areas: pharmacy leadership, staffing and scheduling, clinical pharmacy services, medication safety, medication supply, regulatory and compliance, team support and financial stewardship. Having supporting toolkits, checklists and guidance for each of the key areas enhances pharmacy department planning for a diverse range of comprehensive patient care services, including increased emergency department and elective surgical services cases that were anticipated during the reboot. Communicating the message clearly to local senior leadership is intertwined throughout the roadmap to support financial stewardship efforts. Various reboot strategies our health system is using are discussed in terms of the 8 key areas with successful implementation suggestions for pharmacy leaders to consider when planning for resiliency.

\section{Setting}

Our health system is a leading provider of health care in the United States with nearly 35 million patient encounters, 1.9 million hospital admissions and 9.2 million emergency department visits annually. Our health system consists of 179 acute care hospitals and nearly 2,000 sites of care including surgery centers, freestanding emergency rooms, urgent care centers and physician clinics in 21 states. Our system employs approximately 5,500 pharmacists.

In a 2019 survey of hospitals in our health system, the majority of pharmacy departments continue to schedule and allocate pharmacists to meet the core clinical pharmacy program elements. Of 133 respondent pharmacy service department teams in these hospitals, $69 \%$ reported the central pharmacy open $24 / 7$ and $66 \%$ reported $\geq 51 \%$ of unit-based pharmacist time dedicated to direct patient care activities during first shift. While pharmacy hours of operation differ depending on hospital characteristics and local community needs, the core clinical pharmacy program elements are provided 24 hours/day, 7 days per week, utilizing remote pharmacy teams. These core elements include antimicrobial management, anticoagulation monitoring, basic nutrition support, intravenous to oral conversion, pain manage- ment, medication safety, skill set and competency expectations, formulary management and visibility and communication.

\section{Pharmacy Leadership: Direct Pharmacy Leaders in Guiding and Supporting Reboot Plans}

To assist pharmacy leadership with planning ahead for potential changes and the resumption of certain patient care areas within the hospital during and following the COVID-19 pandemic, a checklist of tasks with accompanying tools to support reboot plans was created. (Table 1) Frequent pharmacy leader communications are recommended with hospital executives for reboot and financial resiliency discussions to assure alignment with hospital goals and for pharmacy services visibility and support during the reboot period.

Additionally, it is recommended that the director of pharmacy meet regularly with the pharmacy team during daily shift huddles and staff meetings for the purpose of departmental awareness and communication. Huddle talking points include addressing the staffing plan to position the team well; reminding the team of the importance of visibility, especially during interdisciplinary rounds; continuing to address medication safety by reporting medication errors; and managing regulatory and compliance changes, such as personal protective equipment (PPE) use and removal of temporary pandemic user access to medications when no longer required.

\section{Staffing and Scheduling: Evaluate Hospital Staffing Model and \\ Strategy}

Incorporating staffing and scheduling plans into the overarching business strategy is essential for pharmacy leaders during this reboot phase. Leaders must understand, optimize and protect pharmacy services staff to ensure that the comprehensive patient care coverage is provided for all patients served based on hospital-specific data during peak, moderate and low volume cycles. As critical care units in some areas of the U.S. continue to surge, pharmacist-to-patient ratios may require adjustment. ${ }^{9}$ 
Table 1. Surgical/Procedural Acceleration Checklist

\begin{tabular}{|c|c|c|c|}
\hline Complete & Task & Start Date & $\begin{array}{l}\text { Completed } \\
\text { Date }\end{array}$ \\
\hline \multicolumn{4}{|c|}{ ASSESS HOSPITAL INVENTORY } \\
\hline & $\begin{array}{l}\text { Assess current inventory of procedural medications (e.g., para- } \\
\text { lytics, sedation medications, antibiotics, reversal agents, blood } \\
\text { pressure medications, narcotics) }\end{array}$ & & \\
\hline \multicolumn{4}{|c|}{ COMPLETE EXPIRATION CHECKING } \\
\hline & $\begin{array}{l}\text { Check anesthesia carts, operating room satellites, and procedural } \\
\text { areas for expired meds }\end{array}$ & & \\
\hline \multicolumn{4}{|c|}{ REFILL PROCEDURAL AREAS TO MAXIMUM PAR LEVELS } \\
\hline & $\begin{array}{l}\text { Increase pars to standard and fill to maximum levels for auto- } \\
\text { mated dispensing cabinets (ADCs) and procedural areas where } \\
\text { medications were unloaded or pars decreased }\end{array}$ & & \\
\hline \multicolumn{4}{|c|}{ CALCULATE NEEDED MEDICATIONS } \\
\hline & $\begin{array}{l}\text { Discuss with operating room staff and physicians/providers antici- } \\
\text { pated surgical cases by day of week, volume, and type }\end{array}$ & & \\
\hline & $\begin{array}{l}\text { Calculate days' supply available for procedural medications based } \\
\text { on historical usage and current medication supply }\end{array}$ & & \\
\hline & $\begin{array}{l}\text { Determine number of medications needed from third party ven- } \\
\text { dors used (e.g., cardioplegia, anesthesia syringes, narcotic drips) } \\
\text { and order with appropriate lead time }\end{array}$ & & \\
\hline & $\begin{array}{l}\text { Order medications for upcoming cases (e.g., use ADC use report to } \\
\text { determine what is needed for future cases) }\end{array}$ & & \\
\hline & $\begin{array}{l}\text { Review operating room schedule the day before surgeries to as- } \\
\text { sess patient needs, staffing, and medication compounding }\end{array}$ & & \\
\hline & Address supply order backorders or substitutions & & \\
\hline & $\begin{array}{l}\text { Order appropriate medications for pre-operative, post-anesthesia } \\
\text { care unit, procedural, and post-operative care areas }\end{array}$ & & \\
\hline \multicolumn{4}{|c|}{ COMMUNICATE WITH ANESTHESIA } \\
\hline & $\begin{array}{l}\text { Communicate product shortages with the anesthesia team and } \\
\text { resolve medication supply concerns before the operating room go } \\
\text { live date }\end{array}$ & & \\
\hline & $\begin{array}{l}\text { Discuss operating room scheduling with the anesthesia team to } \\
\text { align medication supply needs with daily replenishment times }\end{array}$ & & \\
\hline \multicolumn{4}{|c|}{ ADDRESS ROUTINE PHARMACY STAFFING NEEDS FOR NORMAL HOURS } \\
\hline & $\begin{array}{l}\text { Review staffing needs and schedule staff at appropriate levels in } \\
\text { the pharmacy the day before go live and the day of go live }\end{array}$ & & \\
\hline & $\begin{array}{l}\text { Review staffing needs and schedule staff at appropriate levels in } \\
\text { the pharmacy several days before go live to allow for compounding } \\
\text { of medications with appropriate beyond use dating }\end{array}$ & & \\
\hline & $\begin{array}{l}\text { Review staffing with remote order verification one day before } \\
\text { go live and the day of go live (e.g., pre-operative/post-operative } \\
\text { orders, administration orders) }\end{array}$ & & \\
\hline \multicolumn{4}{|c|}{ DETERMINE PHARMACY STAFFING NEEDS FOR EXTENDED HOURS } \\
\hline & $\begin{array}{l}\text { Review weekend staffing needs in the main pharmacy and phar- } \\
\text { macy satellites }\end{array}$ & & \\
\hline & $\begin{array}{l}\text { Plan ADC refills and compounding in those areas over extended } \\
\text { hours including weekends, if necessary }\end{array}$ & & \\
\hline & $\begin{array}{l}\text { Assess remove order verification staffing needs for after hours and } \\
\text { weekends }\end{array}$ & & \\
\hline
\end{tabular}


Table 1. Con't

\begin{tabular}{|c|c|c|c|}
\hline Complete & Task & Start Date & $\begin{array}{l}\text { Completed } \\
\text { Date }\end{array}$ \\
\hline \multicolumn{4}{|c|}{ ENSURE PHARMACIST EDUCATION AND TRAINING FOR UNITS COVERED } \\
\hline & $\begin{array}{l}\text { Provide education and training for pharmacists scheduled in units } \\
\text { (i.e., critical care and surgical units) they do not typically cover }\end{array}$ & & \\
\hline & $\begin{array}{l}\text { Review surgical prophylaxis guidance with pharmacists scheduled } \\
\text { to cover surgical units }\end{array}$ & & \\
\hline & $\begin{array}{l}\text { Provide a refresher for automated dispensing cabinets in anesthe- } \\
\text { sia/operating room areas for pharmacists scheduled to cover surgi- } \\
\text { cal/operating room areas }\end{array}$ & & \\
\hline \multicolumn{4}{|c|}{ ASSESS OPERATING ROOM SAFETY } \\
\hline & $\begin{array}{l}\text { Verify pharmacy prepares standardized solutions and medications } \\
\text { requiring compounding and dilution, particularly high-alert medica- } \\
\text { tions }\end{array}$ & & \\
\hline & Assure tallman lettering is in use & & \\
\hline & Validate all medications are clearly labeled & & \\
\hline & Pharmacy restocks and standardizes medication trays & & \\
\hline & Avoid purchasing look-alike products & & \\
\hline & Assure order sets are used & & \\
\hline & Perform bar code medication administration if available & & \\
\hline & Use smart pumps for medication infusions & & \\
\hline
\end{tabular}

Our roadmap also includes a staffing model tool that calculates the number of staff needed to provide care based on patient volume.

(Table 2) Remote order verification pharmacist service needs are determined based on volume and budgeted by hour. Technician staffing, particularly for compounding, as patient volumes increase, is also a consideration (e.g., evaluate batching needs with future operating room schedules, beyond use dating of products and PPE availability). A pharmacy services staffing assessment detects gaps in departmental scheduling (i.e., shifts covered) and pharmacist-to-patient ratio allocation. This is particularly useful to determine the need to increase staff for surgical services, emergency departments and critical care areas as volumes return to baseline.

\section{Clinical Pharmacy Services: Guide Clinical Pharmacists to Optimally Care for Patients and Preserve Financial Resiliency}

Many of our hospitals have unit-based clinical pharmacists rounding with interdisciplinary teams. As a result of COVID-19 patient surges that continue, pharmacists who do not typically cover critical care units may be scheduled to provide care for the most critically ill patients. Education and training must be provided to ensure competence of rounding clinical pharmacists. ${ }^{9,10}$ A two-tiered approach has been recommended, allowing more experienced pharmacists to direct the less-experienced. ${ }^{9}$ Anticipating the need for education, a critical care series primer and treatment guidelines are available as resources to cross-covering pharmacists for critically ill patients. ASHP's toolkit for patient surge management may be helpful, especially in predicting certain medication needs for the care of COVID-19 patients."

To prepare for redeploying clinical pharmacists back to the unit-based model, clinical pharmacy managers are reviewing and sharing the importance of making clinical pharmacists available and easily accessible to physicians, nurses and leadership. Working with the interdisciplinary team will allow pharmacists to provide patients with the best possible care. Basic pharmacy services guidance and expectation of care are included for medication safety, antimicrobial management program and pharmacy directed services (e.g. anticoagulation monitoring, nutrition support, intravenous to oral conversion, 
Table 2. Pharmacy Services Volume-Based Staffing Considerations

\section{Instructions:}

For the patient care area with unit-based pharmacist coverage before COVID-19, please use the information below and in Table 3 to assess pharmacy services volume-based staffing considerations. An example for the Critical Care patient care area is provided at the bottom of this table.

1. Name of Patient Care Area (Column 1):

2. Pre-COVID-19 Baseline Patient Volume: __ number of patients

3. Unit-based pharmacist coverage before COVID-19: __ pharmacist FTE __ hours/day ___ days of week

4. Post-COVID-19 Patient Volume: ___ total number of patients on patient care area patients on patient care area COVID-19+

5. Determine volume increase back to baseline before COVID-19 (Column 2): Post-COVID-19 patient volume / Pre-Covid-19 baseline patient volume $\times 100 \%$

6. Determine percent COVID-19+ patients for the patient care area, if applicable (Column 4): number of patients on patient care area COVID-19+/total number of patients on patient care area $\times 100 \%$

7. Using percent results in Columns 2 and 4 , locate the closest match in Column 3 to determine percent unit-based pharmacist hours to staff

8. Determine recommended pharmacist FTE for the patient care area: Percent Unit-Based Pharmacist Hours to Staff result (Column 3) x pharmacist FTE before COVID-19

Note the staffing requirements will change based on number of patients, severity of illness, and preCOVID-19 staffing.

\begin{tabular}{|l|c|c|c|}
\hline $\begin{array}{c}\text { Column 1: Patient Care } \\
\text { Area }\end{array}$ & $\begin{array}{c}\text { Column 2: Volume In- } \\
\text { crease Back to Baseline } \\
\text { Before COVID-19 }\end{array}$ & $\begin{array}{c}\text { Column 3: Percent Unit- } \\
\text { Based Pharmacist Hours } \\
\text { to Staff* }\end{array}$ & $\begin{array}{c}\text { Column 4: Percent } \\
\text { COVID-19+ Patients }\end{array}$ \\
\hline $\begin{array}{l}\text { Surgical Services } \\
\text { (Medical/Surgical Units } \\
\text { Reopened) }\end{array}$ & $50 \%$ & Staff at 25-50\% & - \\
\cline { 2 - 4 } & $75 \%$ & Staff at 50-75\% & - \\
\hline \multirow{2}{*}{$\begin{array}{l}\text { Emergency } \\
\text { Department }\end{array}$} & $100 \%$ & Staff at 75-100\% & - \\
\cline { 2 - 4 } & $50 \%$ & Staff at 25-50\% & - \\
\cline { 2 - 4 } & $75 \%$ & Staff at 50-75\% & - \\
\hline Critical Care & $100 \%$ & Staff at 75-100\% & - \\
\cline { 2 - 4 } & $50 \%$ & Staff at 25-50\% & $25-50 \%$ \\
\cline { 2 - 4 } & $75 \%$ & Staff at $50-75 \%$ & $50-75 \%$ \\
\cline { 2 - 4 } & $100 \%$ & Staff at 75-100\% & $75-100 \%$ \\
\hline
\end{tabular}

\section{Example:}

1. Name of Patient Care Area (Column 1): Critical Care

2. Pre-COVID-19 Baseline Patient Volume: 30 patients

3. Unit-based pharmacist coverage before COVID-19:

a. 1 pharmacist FTE 8 hours/day Mo-Fr days of week

4. Post-COVID-19 Patient Volume: 15 patients:

a. 11 non-COVID-19 patients, 4 patients COVID-19+

5. Volume increase back to baseline before COVID-19 (Column 2):
a. $15 / 30 \times 100 \%=50 \%$

6. Determine percent COVID-19+ patients for the patient care area, if applicable (Column 4): 4/15 × 100\% $=\sim 25 \%$

7. Using percent results in Columns 2 (50\%) and 4 (25\%), locate the closest match in Column 3 to determine percent unit-based pharmacist hours: The closest match is Staff at $50-75 \%$. Since the Percent COVID-19+ Patients result (Column 4) is $25 \%$, Staff at $50 \%$ is chosen in this example.

8. Determine recommended pharmacist FTE for the patient care area: Staff at $50 \% \times 1$ pharmacist FTE before COVID-19 = 0.5 pharmacist FTE recommended for this post-COVID-19 ICU patient volume

*Assumes unit-based pharmacist coverage for patient care area before COVID-19

${ }^{+}$Considers COVID-19 patient complexity with the assumption that these patients require a similar amount of care in non-Critical Care units. However, if hospitals have COVID-19 units or more severely ill patients, then this table may be adjusted accordingly based on patient acuity. 
pain management). Clinical pharmacy services performance demonstrates contributions to our health system's overall financial stewardship.

To assist with the reboot of surgical services, a surgical and procedural operations acceleration checklist was implemented. (Table 1) This checklist provides detailed directions on medication management processes to restart surgical procedures with the appropriate medication supply and stock, and important medication safety components specific to the operating room. To assure safe practices, the ASHP Guidelines on Perioperative Pharmacy Services is an encouraged primer to the surgical services reboot. ${ }^{12}$

\section{Medication Safety: Provide Tools to Assess Safe Practices}

Medication safety continues to be a priority during COVID-19 and the reboot phase. Critically ill patients with COVID-19 requiring ventilator support have complicated medication regimens that may include neuromuscular blocking agents (e.g., cisatracurium, vecuronium), anticoagulants for venous thromboembolism prophylaxis, medications for the treatment of COVID-19, bronchodilators (e.g., albuterol, levalbuterol) and anxiolytic and sedatives. During periods of COVID-19 surges, non-critical care units are converted to critical care units to manage the additional patient volumes. A medication safety playbook is used to emphasize the importance of sharing medication events and errors with the team to improve safety from a systems perspective.

Earlier in the year, a medication safety audit tool was released to assess patient care unit and pharmacy services. The most pertinent sections of the tool, regarding the use of neuromuscular blocking agents and anticoagulation medication safety, are being used to identify and address gaps in the system that may potentially lead to medication errors for units converted to critical care..$^{13}$ (Table 3) Routine assessment of operating room medication safety practices using recommendations from Wahr et al. may reveal a drift in safety practices that have occurred during COVID-19.14 When gaps in safety practices are identified, creating an action plan may be helpful to close gaps with the responsible person(s) and corresponding timeline clearly delineated.

\section{Medication Supply: Offer Medication Shortage, Conservation and Future Supply Planning Guidance}

As patient volumes increase, hospitals confirm a sufficient medication supply is in inventory to safely provide patient care. Automated dispensing cabinet supplies are adjusted for patient volumes based on projection of services. Savings plans and clinical initiatives are evaluated to support hospital financial health (e.g., biosimilar medications, formulary conversions) with guidance that remote, abbreviated Pharmacy and Therapeutics Committee meeting structures are considered for formulary modifications. Review of medication supply is part of the daily huddle discussion along with educating nursing teams on different medication strengths, sizes and concentrations.

Our supply chain team monitors medication supply back-orders and provides alternatives to medications in short supply. Any medications provided by third party vendors (i.e., 503B pharmacies/outsourcers and/or 503A pharmacies) continue to be evaluated to identify whether it would be more cost effective to compound those medications within the hospital. If medications are less costly to outsource from vendors, medication orders are placed in advance with quantities estimated based on projected patient volumes. Personal protective equipment (PPE), such as gloves and gowns used during medication compounding, are necessities that the supply chain team procures and manages. Hospital staff is provided the appropriate PPE based on the pharmacist role by the PPE Czar daily. The PPE Czar role was created in each hospital to assist with monitoring and allocating appropriate PPE to employees. Universal masking in patient and visitor areas of the hospital is a continued practice.

\section{Regulatory Compliance: Ensure Pharmacy Practices Return to Regulatory Compliance Standards}

During COVID-19 surges, nurses and providers 
Table 3. Neuromuscular Blocking Agent and Anticoagulant Safety Checklist

\begin{tabular}{|c|c|c|c|c|c|}
\hline \multicolumn{6}{|c|}{ NEUROMUSCULAR BLOCKING AGENT (NMB) SAFETY } \\
\hline ID & Observations & Location & Discipline & Participant(s) & Responses \\
\hline \multicolumn{6}{|c|}{ PHARMACY: NMB SAFETY } \\
\hline 1 & $\begin{array}{l}\text { Are NMBs segregated from all other medica- } \\
\text { tions in the pharmacy (i.e., placed in separate } \\
\text { lidded containers in the refrigerator or other } \\
\text { secure isolated storage area)? }\end{array}$ & & & & \\
\hline 2 & $\begin{array}{l}\text { Are auxiliary labels placed on all storage bins } \\
\text { and/or automated dispensing cabinets (ADC) } \\
\text { pockets and drawers that contain NMBs, and } \\
\text { all final medication containers of NMBs (e.g., } \\
\text { syringes, IV bags) state: "WARNING: PARALYZ- } \\
\text { ING AGENT - CAUSES RESPIRATORY ARREST } \\
\text { - PATIENT MUST BE VENTILATED" to clearly } \\
\text { communicate that respiratory paralysis will oc- } \\
\text { cur and ventilation is required? }\end{array}$ & & & & \\
\hline \multicolumn{6}{|c|}{ PATIENT CARE UNITS: NMB SAFETY } \\
\hline 3 & $\begin{array}{l}\text { Is NMB storage restricted to only those patient } \\
\text { care units where they are routinely needed (i.e., } \\
\text { perioperative, labor and delivery, critical care/ } \\
\text { intensive care, and emergency settings)? }\end{array}$ & & & & \\
\hline 4 & $\begin{array}{l}\text { As temporary workforce nurses are deployed } \\
\text { in patient care areas where NMBs are routinely } \\
\text { needed, are nurses educated on high-risk medi- } \\
\text { cations and safe guards to reduce harm? }\end{array}$ & & & & \\
\hline 5 & $\begin{array}{l}\text { In patient care areas where used (e.g., ICU), are } \\
\text { NMBs placed in a sealed box or preferably in a } \\
\text { rapid sequence intubation kit? }\end{array}$ & & & & \\
\hline 6 & $\begin{array}{l}\text { If vials are stored in ADCs, are they kept in } \\
\text { lock-lidded pockets or lidded bins in the refrig- } \\
\text { erators (except RSI kits)? }\end{array}$ & & & & \\
\hline 7 & $\begin{array}{l}\text { Does the ADC clinical alert prompt during NMB } \\
\text { removal? WARNING: PARALYZING AGENT, } \\
\text { CAUSES RESPIRATORY ARREST. IS THE PA- } \\
\text { TIENT VENTILATED or IN THE PROCESS of } \\
\text { BEING VENTILATED? }\end{array}$ & & & & \\
\hline 8 & $\begin{array}{l}\text { Are nurses able to access NMBs via override } \\
\text { (RSI kit not included)? NOTE: NMBs should NOT } \\
\text { be available on override in the ADC. }\end{array}$ & & & & \\
\hline 9 & $\begin{array}{l}\text { Was the ADC override report reviewed in the } \\
\text { past } 48 \text { hours to evaluate access or process } \\
\text { issues requiring overrides? Document time } \\
\text { elapsed between last review and today's date. }\end{array}$ & & & & \\
\hline \multicolumn{6}{|c|}{ QUALITY PROCESSES AND RISK MANAGEMENT } \\
\hline 10 & $\begin{array}{l}\text { What do you predict the next medication error } \\
\text { will be? }\end{array}$ & & & & \\
\hline
\end{tabular}


Table 3. Con't

\begin{tabular}{|c|c|c|c|c|c|}
\hline \multicolumn{6}{|c|}{ ANTICOAGULANT SAFETY } \\
\hline ID & Observations & Location & Discipline & Participant(s) & Responses \\
\hline \multicolumn{6}{|c|}{ INTRAVENOUS INFUSION HEPARIN SAFETY } \\
\hline 11 & $\begin{array}{l}\text { Are smart pumps in use to infuse IV heparin } \\
\text { (e.g., assess patient care unit(s))? }\end{array}$ & & & & \\
\hline 12 & $\begin{array}{l}\text { Is error-reduction software employed on all } \\
\text { smart pumps for heparin administration (e.g., } \\
\text { soft and hard maximums)? }\end{array}$ & & & & \\
\hline 13 & $\begin{array}{l}\text { Is commercially available IV heparin admixture } \\
\text { used? }\end{array}$ & & & & \\
\hline 14 & $\begin{array}{l}\text { Is heparin provided in a standard concentration } \\
\text { for IV administration (e.g., } 100 \text { units } / \mathrm{mL} \text { )? }\end{array}$ & & & & \\
\hline 15 & $\begin{array}{l}\text { For IV administration via smart pump, is heparin } \\
\text { set up to infuse in units } / \mathrm{kg} / \mathrm{hr} \text { or } \mathrm{mL} / \mathrm{hr} \text { ? [Best } \\
\text { practice set-up does not require nursing to per- } \\
\text { form calculations.] }\end{array}$ & & & & \\
\hline \multicolumn{6}{|c|}{ ANTIDOTE AND REVERSAL AGENT SAFETY } \\
\hline 16 & $\begin{array}{l}\text { The hospital has a policy that identifies anti- } \\
\text { coagulant antidotes and reversal agents that } \\
\text { can be administered immediately in emergency } \\
\text { situations? }\end{array}$ & & & & \\
\hline 17 & $\begin{array}{l}\text { Does the hospital have standard processes in } \\
\text { place to ensure all identified agents are readily } \\
\text { available where needed (e.g., automated dis- } \\
\text { pensing cabinets, pharmacy storage)? }\end{array}$ & & & & \\
\hline 18 & $\begin{array}{l}\text { Do reversal order sets and protocols exist for } \\
\text { all anticoagulant medications identified in the } \\
\text { policy? }\end{array}$ & & & & \\
\hline \multicolumn{6}{|c|}{ QUALITY PROCESSES AND RISK MANAGEMENT } \\
\hline 19 & $\begin{array}{l}\text { Are ready-to-use concentrations being utilized } \\
\text { (nursing does not have to perform manipulation } \\
\text { before administration)? }\end{array}$ & & & & \\
\hline
\end{tabular}

are given access or expanded access to medications. The reboot roadmap requirements include initiating hospital processes to remove user access when no longer needed and to verify compliance with end dates for exceptions to regulations issued by the DEA as a result of COVID-19. Review of pharmacy processes, such as compounding and security of medications adjusted, to convert back to previous elements of performance or regulatory standards is recommended. Resuming USP < 797> and USP $<800>$ construction placed temporarily on hold during COVID-19 is an important consideration to complete and meet regulatory requirements.
Team Support Opportunities: Communicating Consistent

\section{Messages}

Our health system continues to have monthly enterprise-wide pharmacy leadership and clinical pharmacy services calls to communicate relevant, timely information. Pharmacy leadership calls are attended by over 500 directors of pharmacy and clinical pharmacy managers. Clinical pharmacy services calls are attended by clinical pharmacists. A weekly pharmacy services newsletter is also emailed to pharmacy services leaders, with instruction for the content to be included in daily staff huddles. All of these communication mechanisms help to 
convey consistent messaging during the reboot phase.

\section{Financial Stewardship: Planning for Resiliency}

Our health system's financial stewardship resiliency plan encompasses 5 distinct areas: inventory management and optimization, labor management, clinical and medication specific initiatives, technology enhancements and revenue. Optimizing supply chain and hospital inventories minimizes excess stock and maximizes value. Assessing hospital acuity and patient load reflects labor utilization to ensure efficiency. Assuring that clinical pharmacy services are continued and patient regimen reviews are conducted daily is critical to enhance patient outcomes and minimize adverse events due to medication therapy. In the clinical pharmacist workflow, our health system's real time surveillance tool was leveraged to prompt pharmacists to address critical medication management issues and assess intervention documentation completeness. Targeting high cost, low evidence medications decreases direct drug spend. Working with senior leadership to limit physician preference is vital to the hospital financial stewardship plan. Evaluating subscription-based technology and off-contract knowledge solutions software for cancellation opportunities provides additional cost savings. Analyzing current billing practices ensures that medications are appropriately billed for reimbursement. Each area individually impacts financial performance, and together, judicious management of all areas results in overall resiliency.

\section{Discussion}

Our health system deployed the reboot roadmap prior to the lifting of stay-at-home restrictions in most communities to prepare our hospitals and continue to adapt and update content based on the ever changing healthcare environment. Feedback indicates that the information is timely and provides direction to move forward during this challenging time. When every expenditure is closely evaluated, this messaging has given pharmacy services an opportunity to demonstrate commitment to patient care and to showcase financial performance contributions.

\section{Conclusion}

Although COVID-19 disrupted our health system pharmacy services, a roadmap of resiliency strategies with accompanying toolkits, checklists and guidance supports pharmacy department planning as comprehensive patient care services are resumed. Reboot tactics are broadly applicable and adaptable to other health systems as pharmacy leaders prepare for increased emergency department visits and elective surgical services cases, in addition to articulating the operational and clinical contributions of pharmacy services.

\section{Acknowledgements}

The authors wish to thank Chenette Burks, PharmD, BCPS, Kimberly Korwek, PhD and Elizabeth Wiggins, PharmD, BCPP, for assistance with manuscript preparation and editing.

\section{Conflicts of Interest}

The authors declare they have no conflicts of interest.

The authors are employees of HCA Healthcare Clinical Operations Group, an organization affiliated with the journal's publisher.

This research was supported (in whole or in part) by HCA Healthcare and/or an HCA Healthcare affiliated entity. The views expressed in this publication represent those of the author(s) and do not necessarily represent the official views of HCA Healthcare or any of its affiliated entities.

\section{Author Affiliations}

1. HCA Healthcare Clinical Operations Group, Nashville, TN

2. HealthTrust Supply Chain, Nashville, TN

\section{References}

1. Centers for Disease Control and Prevention. CDC COVID Data Tracker: United States COVID-19 Cases and Deaths by State. https:// covid.cdc.gov/covid-data-tracker/. Accessed April 20, 2020.

2. Secon H. Almost half of all Americans have been ordered to stay at home. This map shows which cities and states are under lockdown - How many people are staying at home? Business Insider. https://www.businessinsider.com/usmap-stay-at-home-orders-lockdowns-2020-3. Published March 27, 2020. Accessed April 20, 2020. 
3. Jauhar S. The Hidden Toll of Untreated IIlnesses. The Wall Street Journal. https://www.wsj.com/ articles/the-hidden-toll-of-untreated-illnesses-11587128385. Published April 17, 2020. Accessed April 20, 2020.

4. American College of Surgeons. Local Resumption of Elective Surgery Guidance. https:// www.facs.org/covid-19/clinical-guidance/resuming-elective-surgery. Published April 17, 2020. Accessed April 20, 2020.

5. Centers for Medicare \& Medicaid Services. Non-Emergent, Elective Medical Services, and Treatment Recommendations. https://www. cms.gov/files/document/cms-non-emergent-elective-medical-recommendations.pdf. Published April 7, 2020. Accessed April 20, 2020.

6. American College of Surgeons, American Society of Anesthesiologists, Association of perioperative Registered Nurses, American Hospital Association. Joint Statement: Roadmap for Resuming Elective Surgery after COVID-19 Pandemic. https://www.facs.org/covid-19/clinical-guidance/roadmap-elective-surgery. Published April 17, 2020. Accessed April 20, 2020.

7. Barker N, Andreoli E, McWilliams T. COVID-19 and its impact on physician compensation. Becker's Hospital Review. https://www.beckershospitalreview.com/covid-19-and-its-impact-onphysician-compensation.html. Published April 6, 2020. Accessed April 20, 2020.

8. Centers for Disease Control and Prevention. Guidelines: Opening Up America Again. https://www.whitehouse.gov/wp-content/ uploads/2020/04/Guidelines-for-Opening-UpAmerica-Again.pdf. Accessed April 20, 2020.

9. Einav S, Hick JL, Hanfling D, et al. Surge capacity logistics: care of the critically ill and injured during pandemics and disasters: CHEST consensus statement. Chest. 2014;146(4 Suppl):e17S-43S. https://doi.org/10.1378/ chest.14-0734

10. Dager W, Bolesta S, Brophy G, et al. An opinion paper outlining recommendations for training, credentialing, and documenting and justifying critical care pharmacy services. Pharmacotherapy. 2011;31(8):829. https://doi.org/10.1592/ phco.31.8.829

11. American Society of Health-System Pharmacists. Patient surge management during a pandemic: toolkit for hospital and health system pharmacy. https://www.ashp.org/-/media/ assets/pharmacy-practice/resource-centers/ Coronavirus/docs/Health-System-Pharmacy-Surge-Toolkit.ashx. Accessed May 26, 2020.

12. Bickham P, Golembiewski J, Meyer T, Murray CG, Wagner D. ASHP guidelines on perioperative pharmacy services. Am J Health Syst Pharm. 2019;76(12):903-920. https://doi.org/10.1093/ ajhp/zxz073
13. Institute for Safe Medication Practices (ISMP). ISMP Targeted Medication Safety Best Practices for Hospitals; 2020. https://www.ismp.org/ guidelines/best-practices-hospitals. Accessed April 20, 2020.

14. Wahr JA, Abernathy JH 3rd, Lazarra EH, et al. Medication safety in the operating room: literature and expert-based recommendations. Br J Anaesth. 2017;118(1):32-43. https://doi. org/10.1093/bja/aew379 